\title{
Allelic loss of tumor suppressor genes in ameloblastic tumors
}

\author{
Laurentia Nodit ${ }^{1}$, Leon Barnes ${ }^{1}$, Esther Childers ${ }^{2}$, Sydney Finkelstein ${ }^{1}$, Patricia Swalsky ${ }^{1}$ \\ and Jennifer Hunt ${ }^{1}$ \\ ${ }^{1}$ University of Pittsburgh Medical Center, Pittsburgh, PA, USA and ${ }^{2}$ Armed Forces Institute of Pathology, \\ Washington, DC, USA
}

\begin{abstract}
Ameloblastoma is an odontogenic tumor with a variety of histologic appearances and an unpredictable biologic behavior. Little is known about allelic losses of tumor suppressor genes in ameloblastomas. This study surveyed DNA damage in ameloblastomas and correlated this with histologic sub-type and clinical outcome. There were 12 ameloblastomas (two peripheral, eight solid, and two unicystic) and three ameloblastic carcinoma studied for loss of heterozygosity of tumor suppressor genes on chromosomes 1p, 3p, 9p,10q, and $17 p$ (L-myc, hOGG1, p16, pten, and p53). The frequency of allelic loss and the intratumoral heterogeneity were calculated. L-myc ( $71 \%$ frequency of allelic loss) and pten ( $62 \%$ frequency of allelic loss) had the most frequent allelic losses. Overall frequency of allelic loss and intratumoral heterogeneity were higher in mandibular and in unicystic tumors and lower in tumors that recurred/metastasized. The rate of allelic loss in the three carcinomas was similar to that seen in benign tumors. The frequency of allelic loss and intratumoral heterogeneity did not correlate with age, gender, histologic subtype, or prognosis. Since tumors that behaved aggressively did not harbor more allelic losses, it is likely that DNA damage in ameloblastomas and ameloblastic carcinomas is sporadic and cumulative. We conclude that other genetic or epigenetic mechanisms may be responsible for malignant behavior in ameloblastic carcinomas.
\end{abstract}

Modern Pathology (2004) 17, 1062-1067, advance online publication, 30 April 2004; doi:10.1038/modpathol.3800147

Keywords: ameloblastoma; ameloblastic carcinoma; allelic loss; loss of heterozygosity; tumor suppressor gene

Ameloblastomas are usually benign, locally aggressive neoplasms derived from the epithelial odontogenic tissues, which are part of the tooth-forming apparatus. They constitute a group of particularly interesting lesions, because they display embryologic components of the developing tooth germ.

Although very rare when viewed in the context of the human tumor pathology, ameloblastoma represents the most common tumor derived from tooth epithelial components, representing between 13 and $24 \%$ of odontogenic neoplasms, depending on the population studied. ${ }^{1,2}$

Ameloblastomas tend to appear in the third to fifth decades of life $^{3}$ with the unicystic type predominating in younger populations. ${ }^{4}$ There is no significant racial or gender predisposition. Because of its origin centrally within the bone of the mandible or maxilla, clinical symptoms may be entirely absent. The most common symptom is painless swelling

Correspondence: Dr JL Hunt, MD, PUH A610, Department of Pathology, University of Pittsburgh Medical Center, 200 Lothrop Street, Pittsburgh, PA 15213, USA.

E-mail: HUNTJL@msx.upmc.edu

Received 8 January 2004; revised and accepted 30 March 2004; published online 30 April 2004 of the affected area, but unhealed extraction sites, draining sinuses, superficial ulceration, and neural involvement have also been described.

Histologically, the tumor consists of central loosely arranged spindle-shaped cells (Figure 1b, c), surrounded by columnar cells with hyperchromatic nuclei, displaying 'reverse polarization' and peripheral palisading, meaning that the nuclei are located away from the basement membrane (Figure 1b). These cellular components simulate the enamel organ.

Ameloblastomas are divided into four categories based on radiological appearance, histological features, and anatomical location: unicystic, multicystic or solid, desmoplastic, and peripheral. ${ }^{3}$ Although ameloblastomas are histologically benign, they have a high rate of local recurrence, which ranges from 15 to $75 \%{ }^{5}$ depending on the type of surgical treatment (conservative versus radical) and, exceptionally, may even metastasize despite their benign appearance. The biologic behavior cannot be predicted on the basis of morphology, although metastases usually follow multiple recurrences. ${ }^{6}$ Also described are ameloblastic carcinomas, which are rare $(1.1-4 \%){ }^{2}$ These tumors are cytologically malignant and may or may not metastasize. 

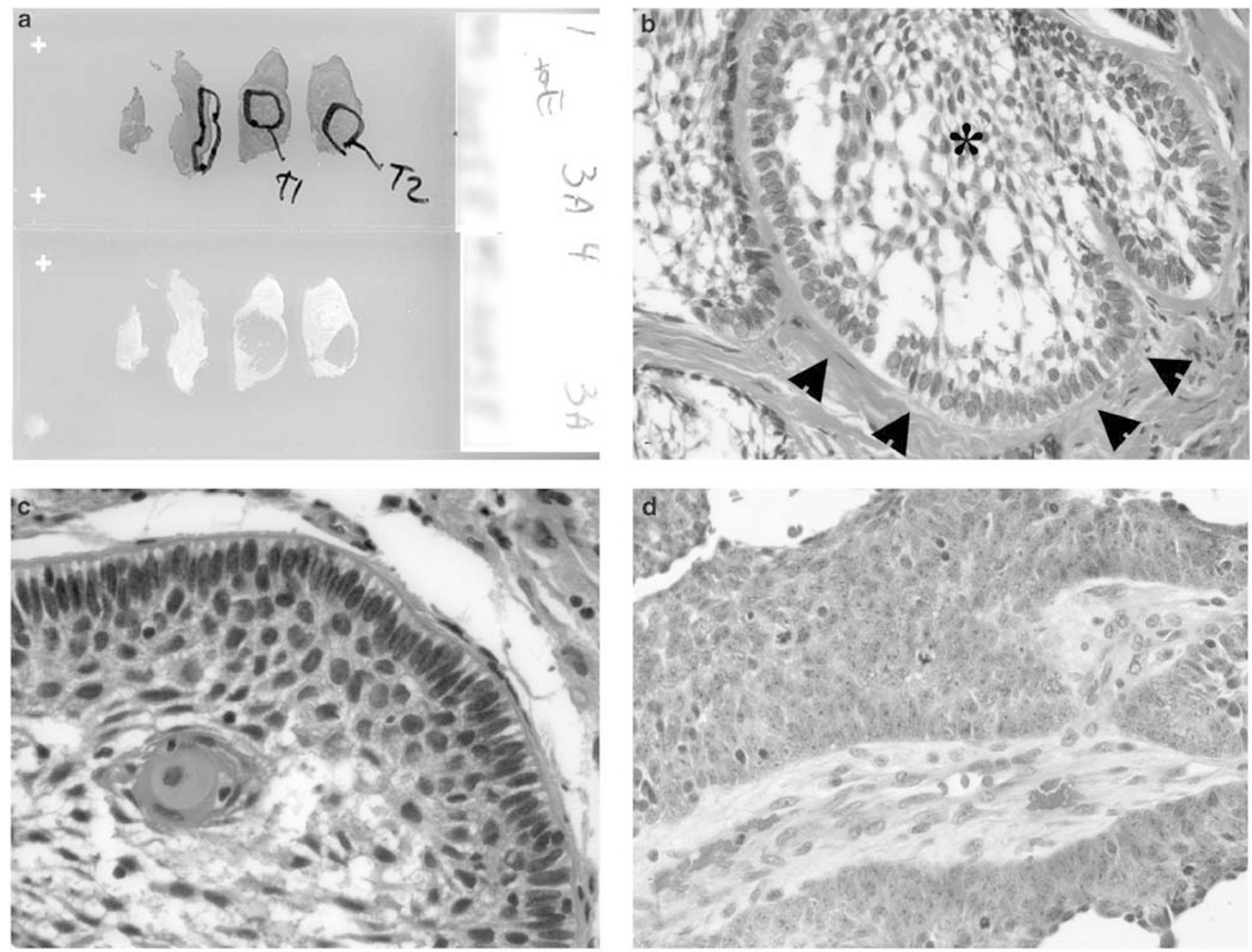

Figure 1 (a) (Image of glass slides). Shows the H\&E slide that was marked with microdissection targets in the top half of the field. The bottom slide is an unstained slide that has been microdissected for the selected targets. (b) (H\&E, $\times 10$, original magnification). Shows the typical arrangement of columnar epithelial cells (arrowheads) that surround the central stellate reticulum $(*)$. (c) $(\mathrm{H} \& \mathrm{E}, \times 20$, original magnification). Demonstrates the appearance of the columnar epithelial cells, with reverse polarization and peripheral palisading. (d) (H\&E, $\times 10$, original magnification). Shows the carcinoma that is described as case 13 in Table 2 . The nuclei are markedly atypical, but the growth pattern still resembles ameloblastic differentiation.

The molecular and genetic characteristics as well as the mechanism of development of ameloblastomas are poorly understood. In this study, we have examined a group of ameloblastomas and ameloblastic carcinomas to measure allelic loss of tumor suppressor genes. We utilized a panel of common tumor suppressor genes to calculate the frequency of allelic loss in microdissected tumor samples and correlated this with the histologic subtype and clinical outcome.

\section{Materials and methods}

\section{Selection of Cases}

This study was approved by the Institutional Review Board. The cases were obtained from the paraffin block archives of the University of Pittsburgh Medical Center, Division of Anatomic
Pathology and The Armed Forces Institute of Pathology (AFIP) to include the diagnoses of ameloblastomas or ameloblastic carcinomas. Cases were selected by the availability of paraffin blocks and confirmation of the diagnosis by conventional histologic re-examination by the authors based on criteria of the World Health Organization Histological Typing of Odontogenic Tumors. ${ }^{3}$ The pathologic information was obtained from the surgical pathology report and from review of the slides, and clinical follow-up information was obtained from the medical record. Owing to difficulty in obtaining DNA from decalcified tissue, only cases with blocks that were not decalcified were included in this study.

Paraffin blocks that included areas of tumor and normal adjacent tissue were used for genotyping analysis. Slides were cut from the block (One H\&E, eight unstained deparaffinized slides, and a final H\&E). The H\&E slides were examined and targets 
that were present throughout the series of slides were selected and marked for microdissection. Tissue was microdissected from the unstained slides under direct visualization using a stereoscopic microscope and a beveled surgical blade (Figure 1a). For all cases, one normal target and two different sites of the tumor were dissected.

\section{Molecular Analysis}

Microdissected tissue was digested with proteinase $\mathrm{K}$ and DNA was extracted. Fluorescent-labeled primers were used that have been designed to yield PCR products with less than 150 base pairs, which is optimal for paraffin-embedded tissue DNA. To evaluate allelic loss, a panel of polymorphic microsatellite markers for multiple genetic loci that are known to be at or near specific tumor suppressor genes were selected for PCR (Table 1). The short tandem repeats were chosen for their high polymorphism rates (ideally $>75 \%$ ) in the general population. All PCR reactions were performed for tumor and normal tissue under the same conditions. Amplification products were detected using capillary electrophoresis with a semi-quantitative analysis (Applied Biosystems 310 analyzer and Genescan software, Foster City, CA, USA).

The PCR products from the normal tissue were analyzed first to determine whether the patient's DNA was informative at each specific marker locus. The software generates a different peak for each differently sized PCR product when the patient is informative at that genetic locus (heterozygous for the short tandem repeat unit). In normal tissue, the peak heights are expected to have a ratio of approximately 1:1, because they are present in equal amounts in normal diploid cells. The tumor PCR products were then analyzed for each of the informative loci. The neoplastic tissue was considered to have loss of heterozygosity (LOH) if the ratio of the two peaks for a specific microsatellite marker was $<0.6$ or $>1.5$.

The frequency of allelic loss (FAL) in each tumor component was defined as the number of chromosomal loci at which allelic loss was observed, divided by the number of markers that were informative. The intratumoral heterogeneity was defined as the number of loci that exhibited a different allelic status (lost vs present) divided by the number of loci that were informative.

The genotyping results were collated for each case and a statistical analysis comparing the clinical, histologic, and genotyping results was performed using SPSS ( $\chi^{2}$ and Student's $t$-test). Differences were considered significant at $P<0.05$.

\section{Results}

A total of 12 cases of ameloblastomas (two peripheral, eight solid, and two unicystic) and three cases of ameloblastic carcinoma were included in the study group. Detailed clinical characteristics at diagnosis are provided in Table 2. There were 10 male and five female patients. The median age was 52 years (range: 12-79 years). The average tumor size was $4.2 \mathrm{~cm}$ (range: $2-7.8 \mathrm{~cm}$ ). Seven patients had a known clinical history of recurrent (6) or metastatic (1) neoplasm. One patient died of disease (patient 1, Table 2) and six patients were lost to follow-up.

The results of molecular analysis are shown in Tables 1 and 2. The average number of informative loci per case was 7 (range: $3-9$ ). Overall, the average rate of allelic loss across all tumors studied was $47 \%$ (range: 17-100\%). The average intratumoral heterogeneity was $19 \%$ (range: $0-71 \%$ ). The specific rates of allelic loss seen for each gene locus studied are given in Table 1. The two genes that exhibited the most allelic losses were $L$-myc $(71 \%$ frequency of allelic loss) and pten (62\% frequency of allelic loss) Among the clinical factors, only the site of the primary tumor had a correlation with the frequency of allelic loss, with higher rates of allelic loss seen in mandibular tumors (56\% frequency of allelic loss vs. $33 \%$ frequency of allelic loss, $P=0.04$ ). Intratumoral heterogeneity was also higher in mandibular tumors (42 vs. $21 \%, P=0.038$ ). Frequency of allelic loss was higher in unicystic tumors (67\%) than in other benign subtypes (44\%), although this did not reach statistical significance.

There was no difference between the carcinomas and the benign ameloblastomas in the molecular

Table 1 Tumor suppressor genes studied, the chromosomal locations, primer sequences, and the overall frequency of allelic loss for each gene

\begin{tabular}{lccllc}
\hline $\begin{array}{l}\text { Tumor } \\
\text { suppressor gene }\end{array}$ & $\begin{array}{c}\text { Chromosome } \\
\text { location }\end{array}$ & Marker & Forward primer $\left(5^{\prime} \rightarrow 3^{\prime}\right)$ & Reverse primer $\left(5^{\prime} \rightarrow 3^{\prime}\right)$ & $\begin{array}{c}\text { Frequency of } \\
\text { allelic loss }\end{array}$ \\
\hline $\begin{array}{l}\text { L-myc } \\
\text { VHL }\end{array}$ & $1 \mathrm{p} 34.2$ & MYCL.5NT & ccgtagcctggcgagactcc & gaaaattcgacgttgttaaag & $10 / 14(71 \%)$ \\
HOGG1 & $3 \mathrm{p} 26$ & D3s.1539 & ccattactctctccatagctag & gaaaatacattacttcgac & $7 / 13(54 \%)$ \\
MTS1/p16 (a) & $3 \mathrm{p} 26$ & D3s.2303 & gttagtatcccaggggagc & ggactgggacagaggtctg & $2 / 11(18 \%)$ \\
MTS1/p16 (b) & $9 \mathrm{p} 21$ & D9s.254 & tatcctgggtaataactgcc & ctcctatttggacgaagtgag & $4 / 7(57 \%)$ \\
Pten (a) & $9 \mathrm{p} 21$ & D9s.251 & tattctgcatgtttatgtg & gaaaattccgaaacatc & $3 / 7(38 \%)$ \\
p53 (a) & $10 \mathrm{q} 23$ & D10s.1173 & ggaggtggaggttgcagtg & ctgacaaatggatattac & $8 / 13(62 \%)$ \\
p53 (b) & $17 \mathrm{p} 13$ & D17s974 & agctgggtgagagtgagac & gtggttggacaattgttaccg & $5 / 10(50 \%)$ \\
& $17 \mathrm{p} 13$ & D17s1289 & gcatggtcttttccattcc & gaatttactgacgaatctccgtc & $3 / 9(33 \%)$ \\
\hline
\end{tabular}


Table 2 Complete clinical and molecular data for each case studied in this series

\begin{tabular}{|c|c|c|c|c|c|c|c|c|}
\hline Case & Туре & Size $(\mathrm{cm})$ & Site & Gender & $\begin{array}{c}\text { Age } \\
\text { (year) }\end{array}$ & Follow-up & $\begin{array}{l}\text { Frequency of } \\
\text { allelic loss (\%) }\end{array}$ & $\begin{array}{l}\text { Intra-tumoral } \\
\text { heterogeneity } \\
\qquad \%)\end{array}$ \\
\hline 1 & Peripheral ameloblastoma & 2.8 & Mandible & M & 53 & Recurrent & 38 & 13 \\
\hline 2 & Peripheral ameloblastoma & 3.2 & Maxilla & $\mathrm{M}$ & 68 & Cure & 29 & 29 \\
\hline 3 & Solid ameloblastoma & Unknown & Mandible & $\mathrm{F}$ & 37 & Cure & 100 & 67 \\
\hline 4 & Solid ameloblastoma & 6 & Mandible & $\mathrm{M}$ & 48 & Recurrent & 44 & 33 \\
\hline 5 & Solid ameloblastoma & 3.5 & Mandible & $\mathrm{M}$ & 76 & Recurrent & 29 & 29 \\
\hline 6 & Solid ameloblastoma & 2 & Mandible & $\mathrm{F}$ & 49 & Unknown & 43 & 43 \\
\hline 7 & Solid ameloblastoma & 7.8 & Maxilla & M & 62 & Recurrent & 57 & 14 \\
\hline 8 & Solid ameloblastoma & 3.5 & Maxilla & M & 34 & Recurrent & 17 & 17 \\
\hline 9 & Solid ameloblastoma & 6 & Maxilla & $\mathrm{F}$ & 67 & Unknown & 29 & 14 \\
\hline 10 & Solid ameloblastoma & 5.5 & Maxilla & M & 62 & Recurrent & 29 & 29 \\
\hline 11 & Unicystic ameloblastoma & 3.3 & Mandible & $\mathrm{M}$ & 26 & Unknown & 57 & 71 \\
\hline 12 & Unicystic ameloblastoma & 4 & Mandible & $\mathrm{M}$ & 76 & Unknown & 80 & 40 \\
\hline 13 & Ameloblastic carcinoma & 3 & Maxilla & M & 12 & Metastatic & 38 & 25 \\
\hline 14 & Ameloblastic carcinoma & Unknown & Mandible & $\mathrm{F}$ & 32 & Unknown & 50 & 0 \\
\hline 15 & Ameloblastic carcinoma & Unknown & Mandible & $\mathrm{F}$ & 79 & Unknown & 67 & 17 \\
\hline
\end{tabular}

profiles. Although the frequency of allelic loss and intratumoral heterogeneity in benign ameloblastomas were lower in tumors that recurred or metastasized, this was not statistically significant.

\section{Discussion}

Ameloblastoma is the most common tumor arising from the epithelial components of the embryonic tooth. ${ }^{1,2,7}$ This epithelium does not undergo differentiation to the point of hard structure formation. Ameloblastomas often occur in the molar-ramus region of the mandible or maxilla and they usually grow slowly in an infiltrating fashion. They may have multiple local recurrences. ${ }^{5,7,8}$ Although most ameloblastomas are histologically and clinically benign, they can cause extensive local destruction by direct invasion, ${ }^{8,9}$ and, rarely may even metastasize despite this bland histologic appearance.

As implied by the name, ameloblastomas resemble the epithelial component of developing tooth germs. Histologically, the main tumor cells are columnar, mimicking pre-ameloblasts of the enamel organ, and show reverse polarization, where the nuclei do not rest on the basement membrane, but are apically located and show peripheral palisading (Figure 1b). The epithelial components surround a central web-like arrangement of spindle-shaped cells that is termed stellate reticulum (Figure 1b, c). The radiographic findings are variable, although most tumors show a clearly demarcated unilocular or multilocular lesion, with or without an associated impacted tooth.

Although ameloblastomas have been divided into categories based on anatomical location, histologic features, or radiographic appearance, there is no indication that these designations have prognostic significance. It has been suggested, however, that unicystic ameloblastomas may behave less aggres- sively than multilocular lesions, especially if associated with an impacted tooth. ${ }^{10,11}$ Furthermore, the prognosis of tumors in the anterior mandible may be better than those arising in the posterior mandible. This difference in behavior may be due to the thick cortical bone surrounding the anterior mandible, which is presumed to be more resistant to infiltrative growth.

Malignant tumors of ameloblastic origin are very rare, and appear in two different scenarios: malignant ameloblastoma, defined as a well-differentiated cytologically benign odontogenic tumor that paradoxically metastasizes, and ameloblastic carcinoma which refers to cytologically malignant tumors that may or may not metastasize (Figure 1d). ${ }^{3,12}$

Although the molecular and genetic characteristics of ameloblastomas are poorly understood, the cloning and characterization of expression of the ameloblastin and amelogenin genes in these tumors supports the hypothesis that ameloblastomas arise from the from dental lamina, the outer enamel epithelium or the inner enamel epithelium. ${ }^{13,14}$ Chromosomal imbalances in ameloblastomas are reported to be rare with losses in chromosomes 22 and 10 being most frequently described. ${ }^{15,16}$ Aneuploidy is more common in ameloblastic carcinomas than ameloblastomas and may predict malignant potential. ${ }^{17}$

Several immunohistochemical studies have been described in the literature as an attempt to understand the mechanism of development of ameloblastomas.

Differences in $p 53$ protein expression in different types of ameloblastomas have implicated tumor suppressor gene alteration as a potential oncogenic mechanism. ${ }^{18,19}$ Apoptotic cell death in ameloblastomas (especially granular cell type) is increased, suggesting that the apoptosis pathways may be also involved in tumorigenesis. ${ }^{20}$ Mutations in the human DNA mismatch repair system do not appear 
to be involved in ameloblastomas. ${ }^{21}$ A gene expression profiling of ameloblastomas by means of a cDNA microarray showed increased expression of the oncogene FOS and tumor-necrosis factor receptor $1 .^{22}$

In our study, we examined a group of ameloblastomas and ameloblastic carcinomas for the presence of accumulated mutational damage in tumor suppressor genes, which have correlated with tumor aggressiveness in other organ systems. ${ }^{23}$ We utilized a series of common tumor suppressor genes in a panel to establish the frequency of allelic loss in microdissected tumor samples.

We included eight multicystic, two unicystic, and two peripheral ameloblastomas and three ameloblastic carcinomas. Our results indicate that there is relatively high frequency of allelic loss in ameloblastic tumors (average of $47 \%$ frequency of allelic loss). In comparing the rates of allelic loss between different types of tumors, we found the highest rate in the unicystic tumors (67 vs 43\%). The most frequent allelic losses occurred in the $L$-myc gene $(71 \%)$ and pten gene $(62 \%)$. There were no significant differences in rates of allelic loss between the benign and malignant tumors (46 vs 52\%, $P=0.71$.

The clinical management of ameloblastic tumors has been controversial in light of the inability of traditional pathologic variables to stratify tumors prognostically. Although malignant ameloblastic tumors are rare, providing clinical prognostic information at the time of biopsy or resection would be quite useful for clinical management and followup of these unique tumors. We were initially hopeful that the genotyping strategy might be able to separate tumors of ameloblastic differentiation into those that may behave in a benign fashion and those that behave malignantly based on the frequency of allelic loss. The data suggest, however, that malignant ameloblastic tumors have similar patterns of loss of heterozygosity in tumor suppressor genes to their benign counterparts and that frequency of allelic loss does not relate to tumor behavior.

While testing for allelic loss of tumor suppressor genes is unlikely to provide clinical prognostic information, it does provide insight into the pathogenesis and biology of these tumors. These data suggest that neoplastic transformation develops along similar pathways in both ameloblastomas and ameloblastic carcinomas, with accumulation of allelic loss at similar rates in the same genes. The similar genotyping panels for tumor suppressor genes also suggest that there are likely to be other variables, such as epigenetic changes, or potential mutations in oncogenes that may be responsible for malignant behavior in ameloblastic carcinomas. Additional work will be necessary to identify mutational or epigenetic events to serve as surrogate markers to predict outcome in ameloblastic tumors.

\section{References}

1 Daley TD, Wysocki GP, Pringle GA. Relative incidence of odontogenic tumors and oral and jaw cysts in a Canadian population. Oral Surg Oral Med Oral Pathol 1994;77:276-280.

2 Mosqueda-Taylor A, Ledesma-Montes C, CaballeroSandoval S, et al. Odontogenic tumors in Mexico: a collaborative retrospective study of 349 cases. Oral Surg Oral Med Oral Pathol Oral Radiol Endod 1997;84:672-675.

3 Kramer IR, Pindborg JJ, Shear M. The World Health Organization histological typing of odontogenic tumours. Introducing the second edition. Eur J Cancer B Oral Oncology 1993;29B:169-171.

4 Keszler A, Dominguez FV. Ameloblastoma in childhood. J Oral Maxillofac Surg 1986;44:609-613.

5 Muller H, Slootweg PJ. The ameloblastoma, the controversial approach to therapy. J Maxillofac Surg 1985;13:79-84.

6 Laughlin EH. Metastasizing ameloblastoma. Cancer 1989;64:776-780.

7 Regezi JA, Kerr DA, Courtney RM. Odontogenic tumors: analysis of 706 cases. J Oral Surg 1978;36:771-778.

8 Rosenstein T, Pogrel MA, Smith RA, et al. Cystic ameloblastoma-behavior and treatment of 21 cases. J Oral Maxillofac Surg 2001;59:1311-1316.

9 Weiss JS, Bressler SB, Jacobs EFJ, et al. Maxillary ameloblastoma with orbital invasion. A clinicopathologic study. Ophthalmology 1985;92:710-723.

10 Holmlund A, Anneroth G, Lundquist G, et al. Ameloblastomas originating from odontogenic cysts. J Oral Pathol Med 1991;20:318-321.

11 Robinson L, Martinez MG. Unicystic ameloblastoma: a prognostically distinct entity. Cancer 1977;40: 2278-2285.

12 Elzay RP. Primary intraosseous carcinoma of the jaws. Review and update of odontogenic carcinomas. Oral Surg Oral Med Oral Pathol 1982;54:299-303.

13 Kumamoto H, Yoshida M, Ooya K. Immunohistochemical detection of amelogenin and cytokeratin 19 in epithelial odontogenic tumors. Oral Dis 2001;7:171-176.

14 Snead ML, Luo W, Hsu DD, et al. Human ameloblastoma tumors express the amelogenin gene. Oral Surg Oral Med Oral Pathol 1992;74:64-72.

15 Barril N, Oliveira PR, Tajara EH. Monosomy 22 and $\operatorname{del}(10)(p 12)$ in an ameloblastoma previously diagnosed as an adenoid cystic carcinoma of the salivary gland. Cancer Genet Cytogenet 1996;91:74-76.

16 Jaaskelainen K, Jee KJ, Leivo I, et al. Cell proliferation and chromosomal changes in human ameloblastoma. Cancer Genet Cytogenet 2002;136:31-37.

17 Muller S, DeRose PB, Cohen C. DNA ploidy of ameloblastoma and ameloblastic carcinoma of the jaws. Analysis by image and flow cytometry. Arch Pathol Lab Med 1993;117:1126-1131.

18 el-Sissy NA. Immunohistochemical detection of p53 protein in ameloblastoma types. East Mediterr Health J 1999;5:478-489.

19 Shibata T, Nakata D, Chiba I, et al. Detection of TP53 mutation in ameloblastoma by the use of a yeast functional assay. J Oral Pathol Med 2002;31:534-538.

20 Kumamoto H. Detection of apoptosis-related factors and apoptotic cells in ameloblastomas: analysis by immunohistochemistry and an in situ DNA nick end-labelling method. J Oral Pathol Med 1997;26: 419-425. 
21 Castrilli G, Piantelli M, Artese L, et al. Expression of hMSH2 and hMLH1 proteins of the human DNA mismatch repair system in ameloblastoma. J Oral Pathol Med 2001;30:305-308.

22 Heikinheimo K, Jee KJ, Niini T, et al. Gene expression profiling of ameloblastoma and human tooth germ by means of a cDNA microarray. J Dent Res 2002;81: 525-530.

23 Hunt JL, LiVolsi VA, Baloch ZW, et al. A novel microdissection and genotyping of follicular-derived thyroid tumors to predict aggressiveness. Hum Pathol 2003;34:375-380. 